\title{
Effects of a low carbohydrate diet on energy expenditure during weight loss maintenance: randomized trial
}

In table 3 of this paper by Ebbeling and colleagues (BMJ 2018;363:k4583, doi:, published 14 November 2018), the heading of the third column with pre-randomization data should read "Mean (standard error)" instead of "Mean (SD)." 